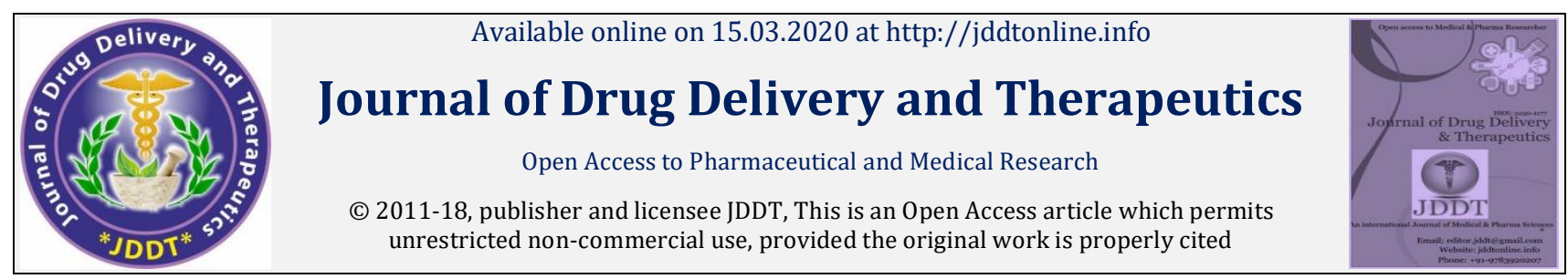

Open 2 Access

Research Article

\title{
Synthesis and characterization of some novel coumarin based various 2- aryl-pyrido [3,2-c] coumarins
}

\author{
Mahesh K. Pandya ${ }^{1}$, Tapan H. Parekh ${ }^{2}$, Mehulsinh R. Chhasatia ${ }^{1}$, Nileshkumar D. Vala ${ }^{1 *}$ \\ ${ }^{1}$ Department of Chemistry Sardar Patel University, Vallabh Vidyanagar, Gujarat, (INDIA) \\ ${ }^{2}$ Department of Chemistry Shree P. M. Patel Instititue of Post Graduate Studies \& Research in applied Science, Affiliated to Sardar Patel \\ University, Vallabh Vidyanagar (Anand), Gujarat, (INDIA)
}

\begin{abstract}
A survey of the literature reveals that the number of coumarin derivatives having heterocyclic moieties either as substituent groups or fused with parent coumarin nucleus possesses a variety of functions and are widely used in drugs and dyes. Because of this wide utility, the synthesis of coumarin has remained a subject of active interest. Looking at the importance of these heterocoumarins and with a view to exploring new methods of their synthesis, the present work was undertaken and this synthesis deals with various 2-aryl-pyrido [3,2-c] coumarins. The compounds have been synthesized by reacting Mannich bases of various 4-hydroxy coumarins with pyridinium salts of various aroyl methyl bromides in the presence of ammonium acetate and acetic acid. All the compounds synthesized have been characterized by analytical and spectral data.
\end{abstract}

Keywords: Pyrido, Coumarins, Krohanke’s reaction.

Article Info: Received 04 Jan 2020; Review Completed 16 Feb 2020; Accepted 26 Feb 2020; Available online 15 March 2020

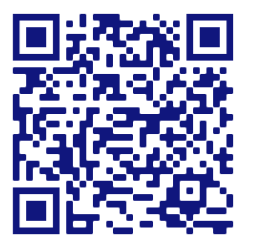

Cite this article as:

Pandya MK, Parekh TH, Chhasatia MR, Vala ND, Synthesis and characterization of some novel coumarin based various 2aryl-pyrido [3,2-c] coumarins, Journal of Drug Delivery and Therapeutics. 2020; 10(2):158-163

http://dx.doi.org/10.22270/jddt.v10i2.3933

Nileshkumar D. Vala, Department of Chemistry Sardar Patel University, Vallabh Vidyanagar, Gujarat, (INDIA)

\section{INTRODUCTION:}

The work incorporated in this series of synthesis of various 2-aryl-pyrido [3,2-c] coumarins. The compounds have been synthesized by reacting appropriate Mannich bases of 4hydroxy coumarins with various aroyl methyl pyridinium bromide salts in the presence of ammonium acetate and acetic acid utilizing Krohnke's mechanism. The structures of all the 2-aryl-pyrido [3, 2-c] coumarins synthesized have been supported by analytical and spectral data.

A literature survey reveals that a very large number of coumarin derivatives containing heterocyclic moieties are used in drugs and dyes. The varied biological activities of the coumarins fused with other heterocycles have encouraged researchers with regard to the procedures and substrates, improving the feasibility of broad families of these compounds. Several biological activities have been claimed for compounds comprising both coumarins and coumarins fused to a pyridine ring. For instance, the coumarin nucleus is present in promising drug candidates as nonpeptidic HIV protease inhibitors [1] such as topoisomerase II [2] and tyrosine kinase [3] inhibitors. Coumarins joined to pyridines have been reported to possess antiallergic [4], anticoagulant [5], antidiabetic [6] activities, and even analgesic [7] properties, being characterized by phenanthrene like structure as found in tetrahydrocannabinol. The pyrido [2,3-c]coumarin skeleton constitutes the backbone of Santiagonamine [8]. This alkaloid has been isolated from Berberis Darvinii (Berberidaceae) and has shown interesting wound healing properties [9-15].

Thus pyrido fused coumarins become an important class of heterocyclic fused coumarin derivatives and therefore brief literature account on various synthetic methods available for pyrido fused coumarins are presented in research work 


\section{Experimental}

2.1 Preparation of 4-hydroxy coumarin, 6-methyl-4-hydroxy coumarin and 8-methyl-4-hydroxy coumarin (1a-c).<smiles>[R]c1ccc(O)c([R2])c1</smiles><smiles>[R]c1cc([R2])c2oc(=O)cc(O)c2c1</smiles>

In a $500 \mathrm{ml}$ round bottom flask attached with a reflux condenser and gas absorption trap, a mixture of appropriate phenol ( 0.2 mole), malonic acid $(22 \mathrm{~g}, 0.2$ mole), anhydrous zinc chloride $(80 \mathrm{~g}, 0.6$ mole) and phosphorous oxychloride (60 ml, 0.4 mole) was heated with stirring at $60-65^{\circ} \mathrm{C}$ for 35 hours. The yellow coloured mixture was cooled and decomposed with water and left overnight. The resulting crude 4-hydroxy coumarin was filtered out, washed with water and dried. This crude product was purified by dissolving it in $10 \%$ sodium bicarbonate solution, filtering and reprecipitating by adding dilute $\mathrm{HCl}$ solution. The 4hydroxy coumarin was separated out as a yellowish-white solid. This was filtered out, washed with water, dried and recrystallized from ethanol-water.

\subsection{Preparation of 6-chloro-4-hydroxy coumarin (1d).}

In a $250 \mathrm{ml}$ round bottom flask fitted with reflux condenser, a mixture of p-chloro phenol $(25.6 \mathrm{~g}, 0.2$ mole), malonic acid(10.4g, 0.1mole) and phosphorous oxychloride $\mathrm{POCl}_{3}$ (30.4 ml) was placed. The reaction mixture was heated for 30 minutes on boiling water bath. It was cooled and poured into ice cold water. The white solid obtained was filtered and washed with cold water. It was then washed with saturated

sodium bicarbonate solution to remove unreacted malonic acid. Finally it was washed with water and dried. Thus diester $\left[\mathrm{CH}_{2}\left(\mathrm{CO}_{2} \mathrm{Ph}-\mathrm{pCl}\right)_{2}\right]$ obtained was recrystallized from ether-hexane. Yield 22g, 68\%, m.p. $115^{\circ} \mathrm{C}$.

The above diester $(20 \mathrm{~g})$ and anhydrous aluminum chloride $(20.6 \mathrm{~g})$ were taken in a round bottom flask. The flask was stoppered and shaken vigorously for 2-3 minutes. A reflux condenser provided with gas absorption tube was attached and the flask was heated in an oil bath at $180-185^{\circ} \mathrm{C}$ for 30 minutes. The reaction mixture was allowed to cool to room temperature and then flask was immersed in an ice bath. The reaction mixture was decomposed by dilute $\mathrm{HCl}$ (1:7) over a period of about 2 hours. The content was then heated on steam bath for 30 minutes with vigorous stirring in order to effect the complete decomposition. The solid product obtained was filtered out and washed with water and dried. The product was then dissolved in 5\% aqueous sodium hydroxide solution and the solution was filtered. The product was then reprecipitated by adding dilute $\mathrm{HCl}$, until solution was acidic. The precipitates were filtered out, washed with water and dried. It was recrystallized from ethyl acetatehexane.

\subsection{Preparation of Mannich bases of 4-hydroxy coumarins(1a-d).}<smiles>[R]c1cc([R])c2oc(=O)cc(O)c2c1</smiles>

In a $100 \mathrm{ml}$ round bottom flask equipped with magnetic stirrer, formaldehyde ( $37 \%$ formalin solution) $(0.025 \mathrm{~mole})$ and ethyl amine $(0.03$ mole) were taken with ethanol $(25 \mathrm{ml})$ and stirred for 30 minutes. Thenafter an appropriate 4hydroxy coumarin $(0.025 \mathrm{~mole})$ dissolved in ethanol $(15 \mathrm{ml})$ was added dropwise to above well stirred solution during 30 minutes at room temperature. The reaction mixture was further stirred at room temperature for overnight. The solid obtained was filtered out and washed with ether and dried. The products were enough pure and were directly used for further reaction.

\section{4 (i) Preparation of phenacyl bromide.}

A solution of acetophenone ( $40 \mathrm{~g}, 0.33$ mole) in anhydrous ether $(60 \mathrm{ml})$ was placed in a three necked flask equipped with a dropping funnel and a gas absorption tube. The flask was placed in an ice bath and was allowed to cool to $0-5^{\circ} \mathrm{C}$. A trace amount of anhydrous $\mathrm{AlCl}_{3}(0.1 \mathrm{~g})$ was introduced and bromine (52.8g, 0.33 mole) was added drop wise with stirring during 30 minutes. The reaction mixture was allowed to come to room temperature and was stirred further for 1 hour. Then pet.ether $\left(40-60^{\circ} \mathrm{C}\right)(100 \mathrm{ml})$ was added. The phenacyl bromide was separated out as white solid. It was filtered out and was washed with a mixture of pet. ether $\left(40-60{ }^{\circ} \mathrm{C}\right)$ and water $(100 \mathrm{ml}, 1: 1)$. It was dried and recrystallized from rectified spirit. 


\section{4 (ii) Preparation of substituted phenacyl bromides.}

An appropriate acetophenone ( 0.5 mole) in acetic acid (100 $\mathrm{ml}$ ) was taken in a three necked flask equipped with a dropping funnel and a condensor with gas absorption tube. Bromine ( 0.5 mole) was added gradually from dropping funnel with stirring at room temperature during 30 minutes. The reaction mixture was stirred for 2 hours at room temperature. It was then poured into ice cold water (500 $\mathrm{ml})$. The substituted phenacyl bromide was separated out as white solid. It was filtered out and washed with water and dried. It was recrystallized from rectified spirit. The following phenacyl bromides were prepared.

2.5 Preparation of aroyl methyl pyridium salts (2a-d).<smiles>[R]c1ccc(C(=O)CC(Br)[R](Br)Br)cc1</smiles>

$(2 a-d)$

An appropriate phenacyl bromide ( 0.25 mole) was dissolved in dry toluene $(100 \mathrm{ml})$ at room temperature. Dry pyridine ( 0.25 mole) was added slowly to the above solution. The reaction mixture was then heated at $100{ }^{\circ} \mathrm{C}$ for 30 minutes. It was then allowed to come to room temperature. Phenacyl bromide pyridinium salt was separated out as a white solid. It was filtered out and washed with dry toluene. It was dried at $60-70{ }^{\circ} \mathrm{C}$ for $4-5$ hours.

\subsection{Synthesis of 2-aryl-pyrido [3, 2-c]coumarins (3a-p).}

In a $100 \mathrm{ml}$ round bottom flask equipped with a magnetic stirrer, aroyl methyl bromide pyridinium salt (2) $(0.006 \mathrm{~mole})$ in glacial acetic acid $(20 \mathrm{ml})$ was taken. To this ammonium acetate $(0.06 \mathrm{~mole})$ was added with stirring at room temperature. Then a solution of appropriate Mannich base of 4-hydroxy coumarin (1) (0.006mole) in glacial acetic acid $(20 \mathrm{ml})$ was added with stirring at room temperature for 15 minutes and the reaction mixture was further stirred for 1 hour at room temperature. Then after the reaction mixture was refluxed for 8 hours at $140{ }^{\circ} \mathrm{C}$. It was then allowed to come to room temperature and was poured into ice-cold water. A sticky mass was separated out which was then extracted with chloroform $(3 \times 30 \mathrm{ml})$. The chloroform layer was then washed with $5 \% \mathrm{NaHCO}_{3}$ and then with water. It was then dried over anhydrous sodium sulphate. The chloroform was removed under reduced pressure. The gummy residue obtained was subjected to column chromatography using silica gel and ethyl acetatecompounds thus obtained were recrystallized from chloroform-hexane.

\section{RESULT AND DISCUSION}

The new method developed in our laboratory for the synthesis of 2-aryl-pyrido [3, 2-c]coumarins, 4-hydroxy coumarin were reacted with the Mannich base of acetophenone under Krohnke's reaction condition. The tautomeric form of 4-hydroxy coumarin undergoes Michael addition with vinyl aroyl ketone, generated insitu from the Mannich base and gives the 1,5-dione intermediate which gets converted into the product in the presence of the $\mathrm{NH}_{4} \mathrm{OAc} / \mathrm{AcOH}$ under Krohnke's reaction condition. Now it is interesting that the compound can also be synthesized by interchanging the functionality of the reacting components. i.e if a Mannich base of the 4-hydroxy coumarin is reacted with the aroyl methyl pyridinium salt under Krohnke's reaction condition, the product obtained will be the same. The Mannich base of the 4-hydroxy coumarin generates the intermediate, coumarin quinone methide which provides the $\alpha, \beta$-unsaturated carbonyl system and Michael addition of aroyl methyl pyridinium salt converts it into a 1,5-dione intermediate which finally gives the product. The research work of is utilized and various 2-aryl-pyrido [3,2-c] coumarine has been synthesized.

The condensation of various Mannich bases (1a-d) with appropriate aroyl methyl pyridinium salts (2a-d), in the presence of ammonium acetate and acetic acid under Krohanke's reaction condition, gave the 2 -aryl-pyrido[3,2c]coumarins (3a-p). 


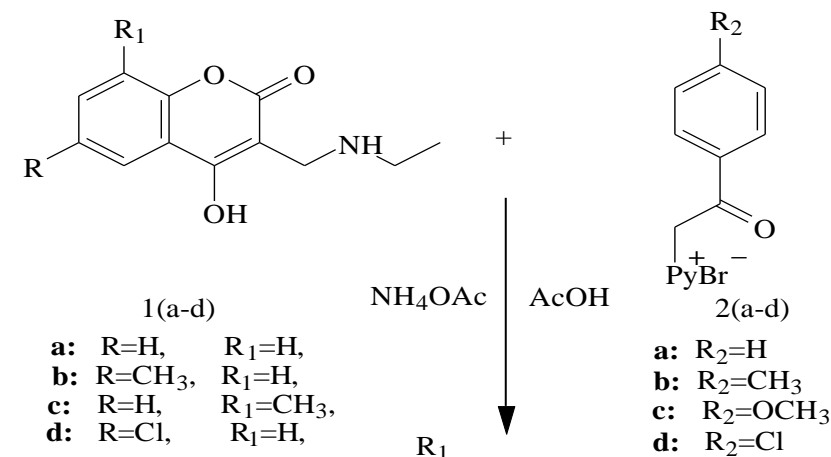<smiles>[R]c1ccc(-c2ccc3c(=O)oc4c([R])cc([R])cc4c3n2)cc1</smiles>

d: $\mathrm{R}_{2}=\mathrm{Cl}$

\begin{tabular}{|c|c|c|}
\hline $\mathrm{a}: \mathrm{R}=\mathrm{H}$ & $\mathrm{R}_{1}=\mathrm{H}$ & $\mathrm{R}_{2}=\mathrm{H}$ \\
\hline $\mathrm{b}: \mathrm{R}=\mathrm{H}$ & $\mathrm{R}_{1}=\mathrm{H}$ & $\mathrm{R}_{2}=\mathrm{CH}_{3}$ \\
\hline $\mathrm{c}: \mathrm{R}=\mathrm{H}$ & $\mathrm{R}_{1}=\mathrm{H}$ & $\mathrm{R}_{2}=\mathrm{OCH}_{3}$ \\
\hline $\mathrm{d}: \mathrm{R}=\mathrm{H}$ & $\mathrm{R}_{1}=\mathrm{H}$ & $\mathrm{R}_{2}=\mathrm{Cl}$ \\
\hline $\mathrm{e}: \mathrm{R}=\mathrm{CH}_{3}$ & $\mathrm{R}_{1}=\mathrm{H}$ & $\mathrm{R}_{2}=\mathrm{H}$ \\
\hline $\mathrm{f}: \mathrm{R}=\mathrm{CH}_{3}$ & $\mathrm{R}_{1}=\mathrm{H}$ & $\mathrm{R}_{2}=\mathrm{CH}_{3}$ \\
\hline $\mathrm{g}: \mathrm{R}=\mathrm{CH}_{3}$ & $\mathrm{R}_{1}=\mathrm{H}$ & $\mathrm{R}_{2}=\mathrm{OCH}_{3}$ \\
\hline $\mathrm{h}: \mathrm{R}=\mathrm{CH}_{3}$, & $\mathrm{R}_{1}=\mathrm{H}$ & $\mathrm{R}_{2}=\mathrm{Cl}$ \\
\hline $\mathrm{i}: \mathrm{R}=\mathrm{H}$ & $\mathrm{R}_{1}=\mathrm{CH}_{3}$ & $\mathrm{R}_{2}=\mathrm{H}$ \\
\hline $\mathrm{j}: \mathrm{R}=\mathrm{H}$ & $\mathrm{R}_{1}=\mathrm{CH}_{3}$ & $\mathrm{R}_{2}=\mathrm{CH}_{3}$ \\
\hline $\mathrm{k}: \mathrm{R}=\mathrm{H}$ & $\mathrm{R}_{1}=\mathrm{CH}_{3}$ & $\mathrm{R}_{2}=\mathrm{OCH}_{3}$ \\
\hline $\mathrm{l}: \mathrm{R}=\mathrm{H}$ & $\mathrm{R}_{1}=\mathrm{CH}_{3}$ & $\mathrm{R}_{2}=\mathrm{Cl}$ \\
\hline $\mathrm{m}: \mathrm{R}=\mathrm{Cl}$ & $\mathrm{R}_{1}=\mathrm{H}$ & $\mathrm{R}_{2}=\mathrm{H}$ \\
\hline $\mathrm{n}: \mathrm{R}=\mathrm{Cl}$ & $\mathrm{R}_{1}=\mathrm{H}$ & $\mathrm{R}_{2}=\mathrm{CH}_{3}$ \\
\hline $\mathrm{o}: \mathrm{R}=\mathrm{Cl}$ & $\mathrm{R}_{1}=\mathrm{H}$ & $\mathrm{R}_{2}=\mathrm{OCH}_{3}$ \\
\hline $\mathrm{p}: \mathrm{R}=\mathrm{Cl}$ & $\mathrm{R}_{1}=\mathrm{H}$ & $\mathrm{R}_{2}=\mathrm{Cl}$ \\
\hline
\end{tabular}

Among the Mannich bases of 4-hydroxy coumarins 1(a-d) used, 1a was known and hence its formation was confirmed by comparison of its melting point with the literature melting point. The (1b, 1c, 1d), were new and their structures were supported by analytical and spectral data.

\section{Compound 1b}

IR: $V_{\max } 1720 \mathrm{~cm}^{-1}(\delta$-lactone carbonyl stretching of coumarin), $1605 \mathrm{~cm}^{-1}$ (aromatic $\mathrm{C}=\mathrm{C}$ stretching), $3365 \mathrm{~cm}^{-1}(\mathrm{O}-$ $\mathrm{H}$ stretching), $3325 \mathrm{~cm}^{-1}$ (N-H stretching), $2960 \mathrm{~cm}^{-1}$ (aliphatic C-H stretching), $3045 \mathrm{~cm}^{-1}$ (aromatic C-H stretching).

NMR: $0.9-1.5 \delta\left(3 \mathrm{H}\right.$, triplet, $\left.-\mathrm{CH}_{2}-\mathrm{CH}_{3}\right), 2.3 \delta(3 \mathrm{H}$, singlet, Ar$\left.\mathrm{CH}_{3}\right)$, 2.6-3.6 $\left(2 \mathrm{H}\right.$ quartet, $\left.-\mathrm{CH}_{2}-\mathrm{CH}_{3}\right), 4.0 \delta\left(2 \mathrm{H}\right.$, singlet, $-\mathrm{CH}_{2}-$ $\mathrm{NH}), 6.8-8.1 \delta(5 H$, multiplet, three aromatic protons,$+ \quad-\mathrm{NH}$ and $-\mathrm{OH}$ protons merged).

\section{Compound 1c}

IR: $V_{\max } 1710 \mathrm{~cm}^{-1}(\delta$-lactone carbonyl stretching of coumarin), $1600 \mathrm{~cm}^{-1}$ (aromatic $\mathrm{C}=\mathrm{C}$ stretching), $3360 \mathrm{~cm}^{-1}(\mathrm{O}-\mathrm{H} \quad$ stretching $), \quad 3340 \mathrm{~cm}^{-1}(\mathrm{~N}-\mathrm{H}$ stretching), $2935 \mathrm{~cm}^{-1}$ (aliphatic C-H stretching), $3055 \mathrm{~cm}^{-1}$ (aromatic C-H stretching).

NMR: $0.9-1.6 \delta\left(3 \mathrm{H}\right.$, triplet, $\left.\mathrm{CH}_{2}-\mathrm{CH}_{3}\right), 2.4 \delta(3 H$, singlet, Ar$\left.\mathrm{CH}_{3}\right), 2.7-3.4 \delta\left(2 \mathrm{H}\right.$, quartet, $\left.\quad-\mathrm{CH}_{2}-\mathrm{CH}_{3}\right), 4.0 \delta(2 \mathrm{H}$, singlet,$\left.\mathrm{CH}_{2}-\mathrm{NH}\right), 6.8-8.0 \delta(5 \mathrm{H}$, multiplet, three aromatic protons + $-\mathrm{NH}$ and $-\mathrm{OH}$ protons merged).

\section{Compound 1d}

IR: $v \max 1715 \mathrm{~cm}^{-1}(\delta$-lactone carbonyl stretching of coumarin), $1610 \mathrm{~cm}^{-1}$ (aromatic $\mathrm{C}=\mathrm{C}$ stretching), $3370 \mathrm{~cm}^{-1}(0$ $\mathrm{H}$ stretching), $3315 \mathrm{~cm}^{-1}\left(\mathrm{~N}-\mathrm{H}\right.$ stretching), $2950 \mathrm{~cm}^{-}$ ${ }^{1}$ (aliphatic $\mathrm{C}-\mathrm{H}$ stretching), $3040 \mathrm{~cm}^{-1}$ (aromatic C-H stretching). 
NMR: $0.8-1.6 \delta\left(3 H\right.$, triplet, $\left.-\mathrm{CH}_{2}-\mathrm{CH}_{3}\right), 2.5-3.7 \delta(2 H$, qurtet, $\mathrm{CH}_{2}-\mathrm{CH}_{3}$ ), $4.0 \delta\left(2 \mathrm{H}\right.$, singlet, $\left.-\mathrm{CH}_{2}-\mathrm{NH}\right), 6.8-8.4 \delta$ ( $5 \mathrm{H}$, multiplet, three aromatic protons $+-\mathrm{NH}$ and $-\mathrm{OH}$ protons merged).

All aroyl methyl pyridinium bromide salts (2a-d) were prepared by using literature method.

The condensation of Mannich bases of 4-hydroxy coumarins (1a-d) with aroyl methyl pyridinium bromide salts (2a-d) under Krohnke's reaction condition proceeded smoothly and gave the expected 2-aryl-pyrido[3,2,-c] coumarin (3a-p) in 55-61\% yield. The structures of all compounds (3a-p) were confirmed by analytical and spectral data.

Thus the reaction of Mannich base of 4-hydroxy coumarin (1b) with aroyl methyl pyridinium bromide salt (2c) gave the expected 2-aryl-pyrido [3,2,-c]coumarin (3g) as yellow solid product.

The IR spectrum of compound ( $3 \mathrm{~g}$ ) showed a strong band at $1715 \mathrm{~cm}^{-1}$ which is due to carbonyl stretching of lactone ring present in coumarin nucleus. The bands observed at 1610 $\mathrm{cm}^{-1}$ and $1430 \mathrm{~cm}^{-1}$ can be assigned to aromatic $\mathrm{C}=\mathrm{C}$ and $\mathrm{C}=\mathrm{N}$ stretching vibrations respectively. Compound showed bands at $1235 \mathrm{~cm}^{-1}$ and $1040 \mathrm{~cm}^{-1}$ which can be attributed to asymmetric and symmetric $\mathrm{C}-\mathrm{O}-\mathrm{C}$ stretching due to the methoxyl group present in the phenyl ring. Compound showed a medium band at $835 \mathrm{~cm}^{-1}$ which can be assigned to $\mathrm{C}-\mathrm{H}$ banding vibration for $\mathrm{p}$-disubstituted phenyl ring present at $\mathrm{C}_{2}$. The compound showed bands at $2930 \mathrm{~cm}^{-1}$ and $3030 \mathrm{~cm}^{-1}$ which can be assigned to aliphatic $\mathrm{C}-\mathrm{H}$ stretching of methyl group attached at $\mathrm{C}_{9}$ and aromatic $\mathrm{C}-\mathrm{H}$ stretching respectively.

The PMR spectrum (60MHz) of compound (3g) showed a singlet $2.5 \delta$ is due to three protons of methyl group present at C9. A methoxyl signal appeared as a singlet at $3.9 \delta$. A multiplet observed between $7.0-9.2 \delta(9 \mathrm{H})$ is due to nine aromatic protons.

The structure of (3g) was further supported by high resolution PMR (300MHz) and ${ }^{13} \mathrm{C}$ spectral data. The PMR $(300 \mathrm{MHz})$ spectrum of compound $(3 \mathrm{~g})$ showed a singlet at $2.49 \delta(3 \mathrm{H})$. This is due to methyl protons attached at $\mathrm{C}_{9}$. A methoxyl signal appeared at $3.90 \delta(3 \mathrm{H})$ as a singlet. A multiplet observed between $7.04-8.54 \delta(9 \mathrm{H})$ is due to nine aromatic protons.

A signal appeared at $21.12 \delta$ is due to methyl carbon attached at $\mathrm{C}_{9}$. A signal appeared at $56.61 \delta$ is for carbon of $-\mathrm{OCH}_{3}$ present in the compound. The signals appeared at 114.62 , $117.13,118.43,119.48,124.80,126.23,129.95,130.63$, $133.23,134.66,136.83,138.02,138.98,151.29$, and $151.95 \delta$, corresponding to fifteen carbons is due to aromatic carbons. The most down field signal appeared at $162.34 \delta$ can be assigned to the carbonyl carbon of the $\delta$-lactone ring of coumarin. In the absence of ${ }^{13} \mathrm{C}$ DEPT spectra the assignment of primary, secondary and tertiary carbons was not possible.

The IR and PMR (60MHz) spectral data for the other compounds (3a-p) are given below.

\section{Compound 3a}

IR: $v \max 1725 \mathrm{~cm}^{-1}(\delta$-lactone carbonyl stretching of coumarin), $1610 \mathrm{~cm}^{-1}$ and $1440 \mathrm{~cm}^{-1}(\mathrm{C}=\mathrm{C}$ and $\mathrm{C}=\mathrm{N}$ stretching), $3035 \mathrm{~cm}^{-1}$ (aromatic C-H stretching).

NMR: $\quad 7.2-9.0 \delta(11 H$, multiplet, aromatic protons).

\section{Compound $3 b$}

IR: $v \max 1720 \mathrm{~cm}^{-1}(\delta$-lactone carbonyl stretching of coumarin), $1600 \mathrm{~cm}^{-1}$ and $1435 \mathrm{~cm}^{-1} \quad(\mathrm{C}=\mathrm{C}$ and $\mathrm{C}=\mathrm{N}$ stretching), $2950 \mathrm{~cm}^{-1}$ (aliphatic stretching of methyl group), $3045 \mathrm{~cm}^{-1}$ (aromatic C-H stretching).

NMR: $2.4 \delta\left(3 H\right.$, singlet, $\left.-\mathrm{CH}_{3}\right), 7.1-9.0 \delta(10 H$, multiplet, aromatic protons).

\section{Compound $3 \mathrm{c}$}

IR: $\quad v \quad \max 1725 \quad \mathrm{~cm}^{-1}(\delta$-lactone carbonyl stretching of coumarin), $1610 \mathrm{~cm}^{-1}$ and $1440 \mathrm{~cm}^{-}$ $1\left(\mathrm{C}=\mathrm{C}\right.$ and $\mathrm{C}=\mathrm{N}$ stretching), $1245 \mathrm{~cm}^{-1}$ (C-O-C stretching), $3035 \mathrm{~cm}^{-1}$ (aromatic C-H stretching).

NMR: $\quad 3.8 \delta\left(3 H, \quad\right.$ singlet, $\left.-\mathrm{OCH}_{3}\right), 7.0$ $8.8 \delta(10 H$,multiplet,aromatic protons $)$.

\section{Compound 3d}

IR: $\quad v \quad \max 1710 \quad \mathrm{~cm}^{-1}(\delta$-lactone carbonyl stretching of coumarin), $1615 \mathrm{~cm}^{-1}$ and $1445 \mathrm{~cm}^{-}$ $1\left(\mathrm{C}=\mathrm{C}\right.$ and $\mathrm{C}=\mathrm{N}$ stretching), $3045 \mathrm{~cm}^{-1}$ (aromatic $\mathrm{C}-\mathrm{H}$ stretching).

NMR: $7.1-9.0 \delta \quad(10 H$, multiplet, aromatic protons).

\section{Compound 3e}

IR: $\quad v \quad \max 1700 \quad \mathrm{~cm}^{-1}(\delta$-lactone carbonyl stretching of coumarin), $1605 \mathrm{~cm}^{-1}$ and $1430 \mathrm{~cm}^{-}$ $1\left(\mathrm{C}=\mathrm{C}\right.$ and $\mathrm{C}=\mathrm{N}$ stretching), $2945 \mathrm{~cm}^{-1}$ (aliphatic $\mathrm{C}-\mathrm{H}$ stretching of methyl group), $3040 \mathrm{~cm}^{-}$ ${ }^{1}$ (aromatic C-H stretching).

NMR: $\quad 2.4 \delta\left(3 \mathrm{H}\right.$, singlet, $\left.-\mathrm{CH}_{3}\right), 7.1-9.0 \delta$ multiplet, aromatic protons).

$(10 H$

\section{Compound $3 \mathrm{f}$}

IR: $v_{\max } 1710 \mathrm{~cm}^{-1}(\delta$-lactone carbonyl stretching of coumarin), $1605 \mathrm{~cm}^{-1}$ and $1435 \mathrm{~cm}^{-1}(\mathrm{C}=\mathrm{C}$ and $\mathrm{C}=\mathrm{N} \quad$ stretching), $\quad 2935 \mathrm{~cm}^{-1}$ (aliphatic $\mathrm{C}-\mathrm{H}$ stretching of methyl group), $3030 \mathrm{~cm}^{-1}$ (aromatic C-H stretching).

NMR: $2.4 \delta\left(6 H\right.$, singlet, two- $\left.\mathrm{CH}_{3}\right), 7.0-$ $9.2 \delta(9 H$, multiplet,aromatic protons $)$.

\section{Compound $3 \mathrm{~g}$}

IR: $v_{\max } 1715 \mathrm{~cm}^{-1}(\delta$-lactone carbonyl stretching of coumarin), $1610 \mathrm{~cm}^{-1}$ and $1430 \mathrm{~cm}^{-1}(\mathrm{C}=\mathrm{C}$ and $\mathrm{C}=\mathrm{N}$ stretching), $1235 \mathrm{~cm}^{-1}$ (C-O-C stretching), $2930 \mathrm{~cm}^{-1}$ (aliphatic C-H stretching of methyl group), $3030 \mathrm{~cm}^{-1}$ (aromaticC-H stretching).

NMR: $2.5 \delta\left(3 H\right.$, singlet, $\left.-\mathrm{CH}_{3}\right), 3.9 \delta(3 H$, singlet,$\left.\mathrm{OCH}_{3}\right), 7.0-9.2 \delta(9 \mathrm{H}$, multiplet, aromatic protons $)$.

\section{Compound $3 \mathrm{~h}$}

IR: $v_{\max } 1715 \mathrm{~cm}^{-1}(\delta$-lactone carbonyl stretching of coumarin), $1615 \mathrm{~cm}^{-1}$ and $1445 \mathrm{~cm}^{-1}(\mathrm{C}=\mathrm{C}$ and $\mathrm{C}=\mathrm{N} \quad$ stretching), $2935 \mathrm{~cm}^{-1}$ (aliphatic $\mathrm{C}-\mathrm{H}$ stretching of methyl group), $3035 \mathrm{~cm}^{-1}$ (aromatic C-H stretching).

NMR: $2.5 \delta\left(3 H\right.$, singlet, $\left.-\mathrm{CH}_{3}\right), 7.0-9.2 \delta(9 H$, multiplet, aromatic protons).

\section{Compound $3 i$}

IR: $v_{\max } 1725 \mathrm{~cm}^{-1}(\delta$-lactone carbonyl stretching of coumarin), $1605 \mathrm{~cm}^{-1}$ and $1440 \mathrm{~cm}^{-1}(\mathrm{C}=\mathrm{C}$ and $\mathrm{C}=\mathrm{N} \quad$ stretching), $\quad 2940 \mathrm{~cm}^{-1}$ (aliphatic $\mathrm{C}-\mathrm{H}$ stretching of methyl group), $3035 \mathrm{~cm}^{-1}$ (aromatic C-H stretching). 
NMR: $2.4 \delta\left(3 H, \quad\right.$ singlet, $\left.-\mathrm{CH}_{3}\right), 7.1-9.0 \delta$

$(10 H$ multiplet, aromatic protons).

\section{Compound $3 \mathbf{j}$}

IR: $v \max 1710 \mathrm{~cm}^{-1}(\delta$-lactone carbonyl stretching of coumarin), $1605 \mathrm{~cm}^{-1}$ and $1430 \mathrm{~cm}^{-1}(\mathrm{C}=\mathrm{C}$ and $\mathrm{C}=\mathrm{N} \quad$ stretching), $\quad 2950 \mathrm{~cm}^{-1}$ (aliphatic C $-\mathrm{H}$ stretching of methyl group), $3050 \mathrm{~cm}^{-1}$ (aromatic C-H stretching).

NMR: $2.5 \delta\left(6 H\right.$, singlet, two- $\left.\mathrm{CH}_{3}\right), 7.0-9.2 \delta$ multiplet, aromatic protons).

$(9 H$,

\section{Compound $3 \mathbf{k}$}

IR: $v_{\max } 1710 \mathrm{~cm}^{-1}(\delta$-lactone carbonyl stretching of coumarin), $1610 \mathrm{~cm}^{-1}$ and $1430 \mathrm{~cm}^{-1}(\mathrm{C}=\mathrm{C}$ and $\mathrm{C}=\mathrm{N}$ stretching), $1250 \mathrm{~cm}^{-1}(\mathrm{C}-\mathrm{O}-\mathrm{C}$ stretching), $2940 \mathrm{~cm}^{-1}$ (aliphatic C-H stretching of methyl group), $3030 \mathrm{~cm}^{-1}$ (aromatic C-H stretching).

NMR: $2.5 \delta\left(3 H\right.$, singlet, $\left.-\mathrm{CH}_{3}\right), 3.9 \delta(3 \mathrm{H}$, singlet,$\left.\mathrm{OCH}_{3}\right), 6.9-8.8 \delta(9 \mathrm{H}, \quad$ multiplet, aromatic protons).

\section{Compound 31}

IR: $v_{\max } 1725 \mathrm{~cm}^{-1}(\delta$-lactone carbonyl stretching of coumarin), $1600 \mathrm{~cm}^{-1}$ and $1435 \mathrm{~cm}^{-1}(\mathrm{C}=\mathrm{C}$ and $\mathrm{C}=\mathrm{N} \quad$ stretching), $\quad 2950 \mathrm{~cm}^{-1}$ (aliphatic $\mathrm{C}-\mathrm{H}$ stretching of methyl group), $3030 \mathrm{~cm}^{-1}$ (aromatic C-H stretching).

NMR: $2.5 \delta\left(3 H\right.$, singlet, $\left.-\mathrm{CH}_{3}\right), 7.2-9.2 \delta(9 H$, multiplet, aromatic protons).

\section{Compound $3 \mathrm{~m}$}

IR: $\quad v \max 1720 \quad \mathrm{~cm}^{-1}(\delta$-lactone carbonyl stretching of coumarin), $1615 \mathrm{~cm}^{-1}$

and $1435 \mathrm{~cm}^{-1}(\mathrm{C}=\mathrm{C}$ and $\mathrm{C}=\mathrm{N}$ stretching $), 3035 \mathrm{~cm}$ ${ }^{1}$ (aromatic $\mathrm{C}-\mathrm{H}$ stretching).

NMR:7.2-9.0 $\delta \quad(10 \mathrm{H}, \quad$ multiplet, aromatic protons).

\section{Compound 3n}

IR: $v_{\max } 1710 \mathrm{~cm}^{-1}(\delta$-lactone carbonyl stretching of coumarin), $1610 \mathrm{~cm}^{-1}$ and $1445 \mathrm{~cm}^{-1}(\mathrm{C}=\mathrm{C}$ and $\mathrm{C}=\mathrm{N} \quad$ stretching), $\quad 2935 \mathrm{~cm}^{-1}$ (aliphatic $\mathrm{C}-\mathrm{H}$ stretching of methyl group), $3055 \mathrm{~cm}^{-1}$ (aromatic C-H stretching).

NMR: $2.5 \delta\left(3 H\right.$, singlet, $\left.-\mathrm{CH}_{3}\right), 7.0-9.0 \delta(9 H$, multiplet, aromatic protons).

\section{Compound 30}

IR: $v_{\max } 1710 \mathrm{~cm}^{-1}(\delta$-lactone carbonyl stretching of coumarin), $1610 \mathrm{~cm}^{-1}$ and $1430 \mathrm{~cm}^{-1}(\mathrm{C}=\mathrm{C}$ and $\mathrm{C}=\mathrm{N}$ stretching $), 1245 \mathrm{~cm}-$ 1 (C-O-C stretching), $3050 \mathrm{~cm}^{-1}$ (aromatic C-H stretching).

NMR: $3.8 \delta\left(3 H\right.$, singlet, $\left.-\mathrm{OCH}_{3}\right), \quad 6.8-8.9 \delta(9 H$, multiplet, aromatic protons).

\section{Compound 3 p}

IR: $v_{\max } 1715 \mathrm{~cm}^{-1}(\delta$-lactone carbonyl stretching of coumarin), $1615 \mathrm{~cm}^{-1}$

and $1425 \mathrm{~cm}^{-1}(\mathrm{C}=\mathrm{C}$ and $\mathrm{C}=\mathrm{N}$ stretching $), 3055 \mathrm{~cm}$ ${ }^{1}$ (aromatic C-H stretching).

NMR: $\quad 7.0-9.2 \delta(9 \mathrm{H}$, multiplet, aromatic protons).

\section{CONCLUSION}

This series deals with synthesis of various 2-aryl-pyrido [3,2c] coumarins. The compounds have been synthesized by reacting Mannich bases of various 4-hydroxy coumarins with pyridinium salts of various aroyl methyl bromides in the presence of ammonium acetate and acetic acid.

\section{REFERENCES}

1. Johannes and G. GerhardGer. Offen., 2,013,262 (1970); CA, 76,87159z (1972).

2. P. Manfred and V. Christos Ger. Offen., 2,553,294 (1977); CA, 87, 103365 (1977).

3. F. Bayer A.-G. Fr. Demande., 2,010,602 (1968); CA, 74, 4703g (1971).

4. N. Otto, D. Alfons, C. W. Schellhammer and B. Otto Ger. 1,794,396 (1974); CA, 82,32468f (1975).

5. U. Hirotoshi, K. Teijiro and K. Kenzo Kogyo Kagaku Zasshi, 73(10),2200 (1970); CA, 74,55115z (1971).

6. S. Kazuaki Japan 7231,391 (1969); CA, 78, 73666s (1973).

7. E. Sigeharu, S. Katsunobu and S. Goichi Ger. Offen., 2,005,933 (1969); CA, 74,65585s (1971).

8. S. S. El-morsy, A. A. Fadda and M. S. El-hossini J. Ind. Chem. Soc., LXV, 699 (1988).

9. K. H. Sinnur and S. SiddappaInd. J. Chem., 25B, 894 (1986).

10. D. I. Brahmbhatt and U. R. Pandya Ind. J. Chem., 40B, 419-21(2001).

11. D. I. Brahmbhatt and B. R. Hirani Ind. J. Chem., 33B, 1072-(1994).

12. D. I. Brahmbhatt , G. B. Raolji, S. U. Pandya and U. R. Pandya Ind.J.Chem., 38B,212-15 (1999).

13. D. I. Brahmbhatt and U. R. Pandya Ind. J. Chem., 42B, 145-49 (2003).

14. R. Crossley, D. E. Beattie, Adrain C.W.Curran, D. G. Hill, and A. E. Lawrence Journal of Medicinal Chemistry, Vol (20), 718-721, (1977).

15. K. L. Kees, T. M. Smith, M. L. McCalep, D. H. Prozialeck, R. S. Cheeseman, T. E. Christos, W. C. Patt, and K. E. Steiner. Journal of Medicinal Chemistry, Vol (35), 944-953, (1992). 